\title{
Graduate nursing student self-assessment: Fundamental technology skills
}

\author{
Thomas James Virgona \\ Adelphi University, New York, United States \\ Correspondence: Thomas James Virgona. Address: 1 South Avenue, Room 232 Alumnae Hall, Garden City, New York \\ 11530, USA. Telephone: 1-516-877-4516. Email: tvirgona@adelphi.edu.
}

Received: July 3, 2012

Accepted: August 20, 2012

Online Published: November 9, 2012

DOI : 10.5430/jnep.v3n3p61

URL: http://dx.doi.org/10.5430/jnep.v3n3p61

\begin{abstract}
A gap exists in technology demands in the nursing field as well as appropriate educational strategies to assist students in developing skills to meet these demands. This study assesses graduate nursing students' perceived skills regarding specific technology related to health care. The results of a brief researcher-developed survey indicated that students' perceived that technology skills were not critical to entering the nursing field, however, they were critical for their present position and essential for promotion. Respondents indicated they had limited opportunities to utilize these technologies and increase their skill sets and the nurses viewed training and barrier reduction as important to adopting new technology skills. Implications for nursing education and practice are presented.
\end{abstract}

\section{Key words}

Health information technology, Education, Nursing

\section{I ntroduction}

Technology will play a pivotal role in the reduction of errors and increase in safety and quality of America's healthcare systems. The U.S. health care system is facing a crisis as it seeks new ways to improve health care quality for the country $^{[1]}$. A gap exists between technology demands and technology skills in the nursing field. Bartholomew ${ }^{[2]}$ reported that $61 \%$ of undergraduate nursing students valued more training in clinical information systems. While most educators agree that these skills must be acquired, a critical component missing from the discussion is specifically which technologies to incorporate into the educational stream. Nurses have a great thirst for technology skills and do not wish to be passive consumers of technology tools ${ }^{[3]}$. The IOM /Robert Woods Johnson Report on the Future of Nursing ${ }^{[4]}$ recommends "reconceptualizing" the role of nurses within the context of the entire workforce, the shortage, societal issues, and current and future technology”.

The enhancement of basic computer skills and incorporation of informatics into nursing curricula is essential and has been recommended by many researchers. Hwang and Parks ${ }^{[5]}$ recommended that enhancement of basic computer skills and incorporation of informatics into the nursing curricula improves the nurses' competency in managing and using healthcare information. McNeil et al. ${ }^{[1]}$ identified the need for specific computer literacy skills, word processing, databases, spreadsheets and email for nurses. With the pending implementation of the electronic health record systems, all of these skill sets are necessary. 
A gap in the nursing literature exists on the perception of students regarding their technology knowledge and skills. Knowledge of these perceptions can assist with targeting appropriate course content to contribute to the acquisition of these skills. This study was undertaken on a convenience sample of graduate students to determine their perceptions of their technology skills and identify barriers to using technology and learning about new technical innovations in nursing.

\section{Literature review}

More than two-thirds of the nursing students sampled $(n=350)$ in a study conducted by Hwang and Park ${ }^{[5]}$ considered their overall informatics competency to be below average. More than half (58.9\%) rated their computer skills to be below average. Significant aspects of this study that was related to informatics competency were basic computer skills and formal informatics education. Hwang and Parks concluded that enhancement of basic computer skills and incorporation of informatics into the formal nursing curricula is needed to improve the nurses' competency in managing and using healthcare information.

Bartholomew ${ }^{[2]}$ reported that out of 186 online student questionnaires completed in their study, $61 \%$ of students valued more training in clinical information systems. Bartholomew and Cipriano ${ }^{[3]}$ through their research into the future of nursing education concluded there is a demand for increased focus on fundamental skill development. Specifically cited in the research was the need for clinical coding and electronic health records management. Basic information security practices are not followed despite the risks involved (e.g., logging off of the system when a staff member leaves the system). Two educational issues were identified as barriers; academics having limited knowledge in these areas and the access to training opportunities are not made known to them in practice.

McNeil et al ${ }^{[1]}$ found the following perceived information technology skills required for entering undergraduate and graduate nursing programs. Six hundred seventy two programs completed the survey. Below is a table outlining his research findings.

Table 1. Perceived information technology skills in Graduate Nursing Programs

\begin{tabular}{|c|c|c|c|c|}
\hline \multirow{2}{*}{ Skill } & \multicolumn{2}{|c|}{ Undergraduate Programs } & \multicolumn{2}{|c|}{ Graduate Programs } \\
\hline & $\mathbf{n}$ & $\%$ & $\mathbf{n}$ & $\%$ \\
\hline Word Processing & 135 & 51 & 108 & 41 \\
\hline Use of e-mail & 124 & 47 & 103 & 39 \\
\hline Use of the internet and WWW & 98 & 37 & 91 & 91 \\
\hline Bibliographic retrieval via library-based resources & 67 & 25 & 76 & 76 \\
\hline Bibliographic retrieval via the internet & 59 & 22 & 69 & 69 \\
\hline Use of presentation graphics software & 24 & 9 & 41 & 41 \\
\hline Database applications & 22 & 8 & 39 & 39 \\
\hline Spreadsheet applications & 21 & 8 & 32 & 32 \\
\hline
\end{tabular}

In the same study, McNeil et al. sought to determine the academic administrative perspective. A survey of 266 deans and directors of baccalaureate and higher nursing programs in the United States indicated that only half of the programs required email and word processing skills of the students entering their undergraduate programs ${ }^{[1]}$. Faculty teaching informatics were also surveyed and rated themselves as "novice” or "advanced beginner" level for teaching information technology content reported that they felt they were actually teaching " information literacy skills" ${ }^{[1]}$.

Missing from much of the published research is specifically which technologies to teach.Kampov-Polevoi and Hemminger ${ }^{[6]}$ discussed curricula in Health Informatics and specifically addressed the inclusion of the Information/ Computer Science Core. Some examples include:

- $\quad$ IT Foundations

- $\quad$ Programming 
- Database Systems

- Systems Analysis and Design

- Human Computer and Human Information Interaction

Saba ${ }^{[7]}$ discussed the future of nursing and suggested that computer technology must be part of the professional nursing practice. McNeil et al went on to specifically define the needed computer literacy skills as; word processing, databases, spreadsheets and email. The use of informatics has been addressed as essential building blocks for evidence-based nursing practice ${ }^{[8]}$. Sherwood ${ }^{[9]}$ also addressed the role of informatics as imperative to prepare these workers that can provide evidenced-based care and implement strategies. Pine ${ }^{[10]}$ argued that Health Information Technology is an integral component of a broader technology restructuring with profound implications for healthcare work and patient health. Computer based education, an alternative that is indeed effective and a legitimate instructional method should also be considered for the nursing fields. This modality can be delivered to nursing students at any time and any location, therefore removing logistical issues ${ }^{[11]}$.

In summary, while little of the reviewed literature actually addressed research on students' perception of their knowledge and skills in technology, the studies reviewed found that students were deficient in skills, valued technology and 'there was a focus on the importance of technology for nursing and for healthcare, the dearth that deans and faculty noted regarding qualified teachers, and the necessary specific technology skills needed in nursing.

\section{Methods}

\subsection{Research purpose and questions}

The purpose of this pilot study was determine technology skill levels of today's nursing graduate students and to describe perceived barriers to using technology and learning about new technical innovation in their field. Many graduate students are returning to universities after years, possibly decades, removed from their last formal education class. Nursing students are no exception. Consequently, many graduate students have learned technology informally or in an adhoc manner. Many more simply have not learned the basic technology fundamentals. The research questions for this study were:

- At what level do nurses perceive their current technology skill?

- What level of technology skills do graduate nursing students need for job acquisition (on entrance, present and for advancement)?

- What are the perceived barriers in the nursing professions to using and learning about new technologies?

\subsection{Sample, setting and instrument}

For this study, a survey developed by the researcher was distributed to graduate nursing students at a mid-sized university in the Mid-Atlantic. The survey was developed because a reliable and valid brief instrument for measuring nurse's use of information systems does not currently exist ${ }^{[12]}$. The Information Systems Use Instrument (ISUI) developed by these researchers measure the frequency of use of hospital information systems, that was not suitable for the purpose of this study. For this survey, the "Technology Skills Assessment Survey "was utilized. The survey contained items for quantitative responses and two questions for qualitative (narrative) responses. The qualitative questions were:

1) What barriers do you personally have to using technology?

2) What barriers to learning new technology or technological innovations are related to your working environment? 
The sample was a group of $(\mathrm{N}=19)$ graduate nursing students enrolled in their first semester of course work; all were practicing RNs.

\subsection{Procedure}

The study was reviewed by the researcher's University IRB and deemed exempt from the need for full review. After this approval, the survey was distributed in a class format. The study was explained and the voluntary nature of participation was discussed. Students who did not wish to participate simply did not complete the survey.

\subsection{Data analysis}

The survey yielded both qualitative and quantitative data. The findings presented below are for two sets of data: the students' quantitative scores for self -assessment of their level of technology skills and their perception of their skills on entrance, at present and those they perceived they needed for advancement in their field (at work); and second, content analysis results of responses to two qualitative questions . For the quantitative data, responses were grouped according to skill level as novice, intermediate and expert .Content analysis, a procedure for reducing qualitative data by coding and categorizing like phrases across responses was used for qualitative data analysis. Results are reported as overall "themes".

The qualitative results of the survey below demonstrate the percent of the total of 19 who responded in any of the three are as follows. For the 19 respondents the number and percent of the total that identified themselves as novice, intermediate, and expert are found in Table 2.

Table 2. Results of Perception of Specific Skills Levels

\begin{tabular}{|c|c|c|c|c|c|c|}
\hline \multirow{2}{*}{ Technology Skill } & \multicolumn{2}{|c|}{ Novice } & \multicolumn{2}{|c|}{ Intermediate } & \multicolumn{2}{|c|}{ Expert } \\
\hline & $\mathbf{n}$ & $\%$ & $\mathbf{n}$ & $\%$ & $\mathbf{n}$ & $\%$ \\
\hline Microsoft Word & 11 & $52.6 \%$ & 6 & $31.6 \%$ & 2 & $10.5 \%$ \\
\hline Microsoft Excel & 15 & $78.9 \%$ & 4 & $21.0 \%$ & 0 & $0.0 \%$ \\
\hline Microsoft PowerPoint & 4 & $21.0 \%$ & 14 & $73.7 \%$ & 1 & $5.2 \%$ \\
\hline eMail & 0 & $0.0 \%$ & 5 & $26.3 \%$ & 14 & $73.7 \%$ \\
\hline HTML & 18 & $94.7 \%$ & 1 & $5.2 \%$ & 0 & $0.0 \%$ \\
\hline Javascript & 19 & $100.0 \%$ & 0 & $0.0 \%$ & 0 & $0.0 \%$ \\
\hline Online Bill Payment & 14 & $73.7 \%$ & 5 & $26.3 \%$ & 0 & $0.0 \%$ \\
\hline Social Networks & 2 & $10.5 \%$ & 15 & $78.9 \%$ & 2 & $10.5 \%$ \\
\hline Smart Phones & 2 & $10.5 \%$ & 14 & $73.7 \%$ & 3 & $15.8 \%$ \\
\hline
\end{tabular}

Table 3.Perception of technology skills required in the nursing field

\begin{tabular}{|c|c|c|c|c|c|c|}
\hline \multirow{2}{*}{ Level of Technology Skill } & \multicolumn{2}{|c|}{ Novice } & \multicolumn{2}{|c|}{ Intermediate } & \multicolumn{2}{|c|}{ Expert } \\
\hline & $\mathbf{n}$ & $\%$ & $\mathbf{n}$ & $\%$ & $\mathbf{n}$ & $\%$ \\
\hline For entrance into your profession & 15 & $78.9 \%$ & 4 & $21.0 \%$ & 0 & $0.0 \%$ \\
\hline For your current position & 3 & $15.8 \%$ & 15 & $78.9 \%$ & 1 & $5.2 \%$ \\
\hline For promotion & 0 & $0.0 \%$ & 4 & $21.0 \%$ & 15 & $78.9 \%$ \\
\hline
\end{tabular}

In reviewing the quantitative responses, it important to note that students viewed technology skills as not critical to enter the nursing field (78.9\% Novice level), but believed they are critical to current positions and for promotion. For Microsoft Office applications, the responses indicated familiarity and comfort with the applications (Word, Excel and Power point), yet a clear view that these skills were not at the expert level. On a specific technology programming question (JavaScript and HTML), all respondents indicated they had no or limited skills that area. As expected social networks and smart phone use were viewed as skills mostly in the intermediate realm. 


\section{Discussion}

It was evident and as expected that advanced skills such as javascript and HTML had the highest percentage of "novice" responders. The "Online Bill Payment" and "Social Network" questions were added to contribute some insight into how nurses perceive self-promoting (limited advertising) functions that have social and personal benefits.The respondents indicated they were at the intermediate level using applications such as Facebook, but lacked skills for online banking. A follow-up discussion in class revealed that nurses considered Facebook to be a 'fun' application with limited risk. However, online banking has financial risks and requires more technology skills.

In analyzing the responses to the qualitative questions regarding what barriers the nurses have to using technology, one major theme that emerged was "exposure". The respondents said they were not exposed to or able to utilize new technologies that would increase their skill sets. This is similar to reports and research indicating that it is not that nurses do not value technology but do not feel they are exposed to it ${ }^{[2]}$.

When responding to what barriers exist to actually learning new technology or technological innovations related to work, the major theme that emerged from coding was "training". This finding is similar to the conclusions of Bartholemew ${ }^{[2]}$. In their responses that were coded, the students reported that in their organizations, there is no in-house training for Microsoft applications, database or any web- based programming language. Further, respondents said that the reason training was a barrier was their perception that the "organizations "do not view certain technology skills as a benefit to a nurse's job function. Interestingly, the respondents indicated in the quantitative section of the survey that they perceived these skills are needed for career advancement. This supported the literature reviewed citing the future of nursing must incorporate these skills ${ }^{[2,3]}$. Often, time for training is an issue that all organizations and staff grapple with, making the notion of computer-based training as suggested by Rohr and Park ${ }^{[11]}$ an attractive option. One model to address the demands for training in the work setting when there is little time or expertise for this training would be collaboration: those instructors teaching informatics in formal education programs and service partners. In summary, and as expected, newly enrolled graduate students viewed themselves for the most part as novices with specific technologies other than social media and smart phones. The students in this study as in others valued technology and saw training and exposure as barriers to learning and adopting new skills.

\section{Limitations}

This study used a small sample size of graduate students in one university and a brief researcher-developed survey so the findings are therefore not generalizeable to other populations. Some skills important for the changing environment of healthcare and the use of electronic records were not addressed in this study. Other technologies that nurses who are graduate students may be proficient in such as bar coding for medications were also not addressed. The purpose of this study was to gain insight for curriculum development and one area that was not assessed, important for graduate studies, was the use of data bases especially those needed for course work and research. These are areas that should be included in future studies.

\section{I mplications and recommendations}

The use of this study's findings for curricula development is important. Erroneous assumptions can be made regarding basic skills that students are purported to have. Although experts in nursing care, it should not be assumed that because they are practicing nurses that they have been exposed to and trained in specific needed technologies. Faculty may want to assess each group of students prior to presenting content on Informatics especially because of these assumptions. Ways to effectively and efficiently train nurses especially on such technology as excel and power point are indicated as foundational to more advanced technologies. 
A replication of this pilot study with other healthcare workers is planned. The descriptive information gleaned from these studies, especially knowing what barriers affect healthcare workers' use and skill with technology, will be used as a springboard to plan for the testing of interventional studies.

\section{Conclusions}

This was an assessment of graduate students' knowledge and skills which was a critical first step in teaching them about technology. Nurses value technology and in general claim that training and exposure are major barriers to learning new technologies in the workplace although they view these as important for advancement. The pairing of academia with service to assist with exposure and training in technology is one model that might be useful to close the gap between demand for technology expertise and nurses’ preparedness along with the use of computer based learning.

\section{Conflict of interest statement}

The author reports no conflicts of interest relevant to this article.

\section{References}

[1] McNeil, B. J., Bickford, C. J., Beyea, S. C., Klappenbach, C. Nursing Infornmation Technology Knowlege, Skills, and Preparation of Student Nurses, Nursing Faculty, and Clinicians: A U.S. Survey. Nursing Information Technology. 2003; 341-349.

[2] Bartholomew, N. Is higher education ready for the information revolution? International Journal of Therapy and Rehabilitation. 2011; 18(10): 558 - 566.

[3] Cipriano, P. F. The Future of Nursing and Health IT: The Quality Elixir. Nursing Economics. 2011; $29(5)$ : $286-282$. PMid:22372088

[4] Institute of Medicine: The future of nursing: Leading change, advancing health. Robert Wood Johnson Foundation and IOM. 2010.

[5] Hwang, J.-I., Park, H.-A. Factors associated with nurses' informatics competency. CIN: Computers, Informatics, Nursing. 2011; 29(10): 256-262. PMid:21076284 http://dx.doi.org/10.1097/NCN.0b013e3181fc3d24

[6] Kampov-Polevoi, J., Hemminger, B. A curricila-based comparison of biomedical and health informatics programs in the USA. Journal of the American Medical Informatics Association. 2011; 18: 195-202. PMid:21292707 http://dx.doi.org/10.1136/jamia.2010.004259

[7] Saba, V. Nursing Informatics: Yesterday, today and tomorrow. International Review. 2001; 48: 177-187.

[8] Bakken, S. An informatics infrastructure is essential for evidenced-based practice. Journal of the American Medical Informatics Association. 2001; 8: 199-201. http://dx.doi.org/10.1136/jamia.2001.0080199

[9] Sherwood, G. Integrating quality and safety science in nursing educatiion and practice. Journal of Research in Nursing. 2011; 16(3): 226-240. http://dx.doi.org/10.1177/1744987111400960

[10] Pine, A. From Healing to Witchcraft: On Ritual Speech and Roboticization in the Hospital. Culture, Medice and Psychiatry. 2011; 262.

[11] Roh, K. R., Park, H.-A. A Meta-Analysis on the Efffectiveness of Computer Based Edication in Nursing. The Korean Society of Medical Informatics. 2010; 16(3): 149-157.

[12] Hudak, C. A., Abdrbo, A. A., Zauszniewski, J. A. Develpment and Testing of Nursing Information Systems Use Instrument. Journal of Nursing Measurment. 2010; 18: 75-82. http://dx.doi.org/10.1891/1061-3749.18.2.75 